\title{
Effect of Cellular Therapy in progression of Becker's Muscular Dystrophy: A Case study
}

\author{
Alok Sharma (1), Hemangi Sane (2), Nandini Gokulchandra (1), Rishabh Sharan (2), Amruta \\ Paranjape (3), Pooja Kulkarni (2), Jayanti Yadav (3), Prerna Badhe (1) \\ (1) Department of Medical Services and Clinical Research, NeuroGen Brain and Spine \\ Institute, Mumbai, India; (2) Department of Research and Development, NeuroGen Brain and \\ Spine Institute, Mumbai, India; (3) Department of Neuro-Rehabilitation, NeuroGen Brain \\ and Spine Institute, Mumbai, India
}

This article is distributed under the terms of the Creative Commons Attribution Noncommercial License (CC BY-NC 4.0) which permits any noncommercial use, distribution, and reproduction in any medium, provided the original author(s) and source are credited.

\begin{abstract}
Becker muscular dystrophy (BMD) is an inherited disorder due to deletions of the dystrophin gene that leads to muscle weakness. Effects of bone marrow mononuclear cell (BMMNC) transplantation in Muscular Dystrophy have shown to be safe and beneficial. We treated a 20year-old male suffering from BMD with autologous BMMNC transplantation followed by multidisciplinary rehabilitation. He presented with muscle weakness and had difficulty in performing his activities. The BMMNCs were transplanted via intrathecal and intramuscular routes. The effects were measured on clinical and functional changes. Over 9 months, gradual improvement was noticed in muscle strength, respiratory functions and North Star Ambulatory Assessment Scale. Functional Independence Measure, Berg Balance Score, Brooke and Vignos Scale remained stable indicating halting of the progression. The case report suggests that cellular therapy combined with rehabilitation may have possibility of repairing and regenerating muscle fibers and decreasing the rate of progression of BMD.

Key Words: Autologous Bone Marrow, Mononuclear cells, Becker Muscular Dystrophy, Manual muscle strength.
\end{abstract}

Eur J Transl Myol - Basic Appl Myol 2016; 26 (1): 61-66

Becker muscular dystrophy (BMD) is an inherited disorder due to the deletions of the dystrophin gene causing muscle weakness. ${ }^{1}$ It is characterized by muscle necrosis that overtakes the regenerative capacity of muscle. The resulting replacement of the muscle by fibrous and fatty tissue leaves muscle increasingly weak and nonfunctional. ${ }^{2}$

Stem cell transplantation may enhance the regenerative ability of damaged and degenerating muscle cells in Muscular Dystrophy (MD). Its efficacy in MD has been explored in many animal studies. ${ }^{3}$ Stem cells can be obtained from a variety of different sources and can have myogenic potential. Cellular Therapy has also been found to be safe and effective for $\mathrm{MD}^{4-6}$ as well as various other neurodegenerative conditions. ${ }^{7}$

The effectiveness of cellular therapy and its influence on the survival of individuals is still unclear due to inadequate sample size and heterogeneous methodologies of patient selection. We hereby present a case of 20 year old male diagnosed as a case of BMD, who underwent transplantations of autologous bone marrow derived mononuclear cells (BMMNC).

\section{Case Report}

A 20 year old male patient, case of BMD having history of initial weakness of lower limb and frequent falls while walking at age of 9 years. He gradually developed severe pain in calves and difficulty in getting up from the floor. At 14 years of age he started facing difficulty in climbing stairs. His symptoms were progressive in nature. He consulted a pediatric neurologist who diagnosed him as a case of muscular dystrophy on the basis of high serum creatine phospho kinase (CPK) level and clinical features. Since a year he is having difficulty in performing overhead activities. At assessment he complained of major difficulty in getting up from floor, or chair, and stair climbing, also has imbalance while walking which leads to frequent falls and difficulty performing his activities of daily livings (ADLs). Patient underwent physiotherapy and was on multivitamins but there was no response noted.

Based on the neurological examination, he was hypotonic and hyporeflexive with proximal muscle weakness more than distal, bilateral tendoachilles 
Cellular Therapy in progression of Becker's Muscular Dystrophy

Eur J Transl Myol - Basic Appl Myol 2016; 26 (1): 61-66

Table 1. Change in the outcome measures over 9 months.

\begin{tabular}{|l|c|c|c|}
\hline Outcome measures & Pre intervention & $\begin{array}{l}\text { Post intervention (3 } \\
\text { months) }\end{array}$ & $\begin{array}{l}\text { Post intervention } \\
\text { (9 months) }\end{array}$ \\
\hline FIM Ambulatory & 113 & 113 & 113 \\
\hline BBS Star & 15 & 37 & 37 \\
\hline $\begin{array}{l}\text { North } \\
\text { Assessment }\end{array}$ & 1 & 15 & 18 \\
\hline Brooke Scale & 3 & 1 & 3 \\
\hline Vignos Scale & 1250 & 3 & 2000 \\
\hline Maximum inspiratory volume & 290 & 1750 & 320 \\
\hline Peak Expiratory Flow Rate & \multicolumn{2}{|c|}{360} & 1 \\
\hline
\end{tabular}

tightness and psuedohypertrophy of calves, deltoids, glutei and forearm muscles bilaterally. He had a waddling gait with wide base of support, hyperextended knees, and hyperlordotic spine. He used to fatigue easily and had occasional chest pain. The maximum inspiratory volume was $1250 \mathrm{ml}$ and Peak Expiratory Flow Rate (PEFR) was $290 \mathrm{ml}$.

His Functional Independence Measure (FIM) score was 113, Berg Balance Score (BBS) was 37/56, North Star Ambulatory Assessment (NSAA) Score was 15/34, Brooke Scale was 1/6 and Vignos Scale was 3/10 (Table 1)

On investigations, CPK levels were elevated (3180IU/1). His musculoskeletal magnetic resonance imaging (MRI - MSK) showed diffuse muscular atrophy and fatty replacement in the bilateral gluteal, thigh, leg, arm and forearm muscles. Electromyography (EMG) showed short duration, low amplitude polyphasic muscle unit action potential suggestive of myopathic process and his 2D Echocardiography and Color Doppler study showed generalized hypokinesia, poor left ventricle contractility and type three LV diastolic dysfunction. The LVEF was $25-30 \%$.

\section{Materials and methods}

The patient was selected for intervention based on the World Medical Associations Helsinki Declaration. The treatment protocol was approved by the Institutional Committee for Stem Cell Research (IC-SCR). Prior to admission, a signed informed consent was obtained from the patient.

A detailed assessment was conducted. Muscles with mMRC MMT (I) score less than 3 and of functional importance like biceps, triceps, glutei, quadriceps, tibialis anterior, hamstrings, abdominals and back extensors were selected for intramuscular transplantation of BMMNC. Motor points were identified and marked by an experienced physiotherapist.

Granulocyte-Colony Stimulating factor (G-CSF) (300 mcg) injections were administered subcutaneously, 48 hours and 24 hours prior to the bone marrow aspiration. ${ }^{8}$ Autologous BMMNCs transplantation was done, with the patient in supine position. Bone marrow was aspirated from the right anterior superior iliac spine. MNCs were separated by the density gradient method. Viable count of the isolated MNCs was taken and was also checked for CD34+ markers by Fluorescence-activated cell sorting (FACS) analysis. $56 \times 10^{6}$ MNCs were diluted in Cerebro Spinal Fluid (CSF) and injected intramuscularly at specific motor points and intrathecally. To reduce the immediate inflammation methyl prednisolone $(1 \mathrm{gm})$ in $500 \mathrm{ml}$ of Ringer lactate solution was administered intravenously. After the cellular therapy, patient underwent neuro rehabilitation, a multidisciplinary rehabilitation protocol including physiotherapy, occupational therapy, psychological counseling and dietary advice. Physiotherapy aimed at maintaining strength of the weak muscles, stretching exercises for the tight muscles, gait and balance training. Occupational therapy aimed at functional training and hand rehabilitation and splinting to prevent hand deformities. Patient was advised for regular therapy at home. Protein enriched high fiber diet was advised to the patient.

\section{Results}

After the cellular therapy the patient was followed up at 3 and 9 months. Improvement was reported after 3 months in his upper limb gross motor function. Overhead activities required comparatively less effort. There was reduction in the stiffness and pseudohypertropy of the calf muscles bilaterally. Significant improvement in standing and sitting posture and balance was observed. Balance in standing and walking had improved. Frequency of falls while walking reduced considerably from 4-5 falls in one month to 1 fall in 3 months. His respiratory functions like maximum inspiratory volume (from $1250 \mathrm{ml}$ to $1750 \mathrm{ml}$ ) and PEFR (from $290 \mathrm{ml}$ to $360 \mathrm{ml}$ ) also improved. 


\section{Cellular Therapy in progression of Becker's Muscular Dystrophy}

Eur J Transl Myol - Basic Appl Myol 2016; 26 (1): 61-66

Table 2. Changes in the muscle strength over 9 months as measured by mMRC-MMT (I) scale

\begin{tabular}{|c|c|c|c|c|}
\hline \multicolumn{2}{|c|}{ Muscle groups } & \multirow{2}{*}{$\begin{array}{l}\text { Pre intervention } \\
3-\end{array}$} & \multirow{2}{*}{$\begin{array}{l}\text { Post intervention (3 } \\
\text { months) } \\
3+\end{array}$} & \multirow{2}{*}{$\begin{array}{l}\text { Post intervention (9 } \\
\text { months) }\end{array}$} \\
\hline Hip & Flexors & & & \\
\hline & Extensors & $2-$ & $2-$ & 2 \\
\hline & Abductors & $2+$ & $2+$ & $2++$ \\
\hline & Adductors & $2-$ & $2+$ & $2+$ \\
\hline \multirow[t]{2}{*}{ Knee } & Flexors & $2++$ & $2++$ & $2++$ \\
\hline & Extensors & $2++$ & $2++$ & $2++$ \\
\hline \multirow{4}{*}{$\begin{array}{l}\text { Ankle and } \\
\text { Foot }\end{array}$} & Tibialis anterior & $3+$ & $3++$ & $3++$ \\
\hline & Tibialis posterior & 4 & 4 & 4 \\
\hline & Plantar flexors & 4 & 4 & 4 \\
\hline & EDL & $3-$ & 3 & 3 \\
\hline \multirow[t]{3}{*}{ Trunk } & $\begin{array}{l}\text { Abdominals } \\
\text { upper }\end{array}$ & $2+$ & $2+$ & $2+$ \\
\hline & $\begin{array}{l}\text { Abdominals } \\
\text { lower }\end{array}$ & $2++$ & $3+$ & $3+$ \\
\hline & Back extensors & $1+$ & 2 & 2 \\
\hline \multirow[t]{3}{*}{ Neck } & Trapezius & 4 & 4 & 4 \\
\hline & Rhomboids & $3++$ & $3++$ & $3++$ \\
\hline & Serratus Ant & $3+$ & $3+$ & $3+$ \\
\hline \multirow[t]{6}{*}{ Shoulder } & Flexors & $3++$ & $3++$ & $3++$ \\
\hline & Extensors & $3+$ & $3++$ & $3++$ \\
\hline & Abductors & $3++$ & $3++$ & $3++$ \\
\hline & Adductors & $3++$ & $3++$ & $3++$ \\
\hline & Ext. rotators & $3+$ & $3++$ & $3++$ \\
\hline & Int. rotators & $3+$ & $3++$ & $3+$ \\
\hline \multirow[t]{4}{*}{ Arm } & Biceps & $3+$ & $3++$ & $3++$ \\
\hline & Brachialis & $3+$ & $3++$ & $3+$ \\
\hline & Triceps & $3+$ & $3++$ & $3++$ \\
\hline & Brachioradialis & $3+$ & $3++$ & $3++$ \\
\hline \multirow{15}{*}{$\begin{array}{l}\text { Forearm, } \\
\text { Wrist and } \\
\text { Hand }\end{array}$} & Supinators & $3++$ & 4 & 4 \\
\hline & Pronators & $3++$ & $4++$ & $3++$ \\
\hline & Wrist Extensors & $3++$ & 4 & 4 \\
\hline & Wrist Flexors & $3++$ & $3++$ & $3++$ \\
\hline & $\begin{array}{l}\text { Flexor } \begin{array}{l}\text { Pollicis } \\
\text { Longus }\end{array} \\
\end{array}$ & $3++$ & 4 & 4 \\
\hline & $\begin{array}{l}\text { Flexor Policis } \\
\text { Brevis }\end{array}$ & $3++$ & $3++$ & $3++$ \\
\hline & $\begin{array}{l}\text { Extensor Pollicis } \\
\text { Longus }\end{array}$ & $3+$ & $3++$ & $3++$ \\
\hline & $\begin{array}{l}\text { Extensor Policis } \\
\text { Brevis }\end{array}$ & $3-$ & $3+$ & $3+$ \\
\hline & Adductor Policis & $3++$ & 4 & 4 \\
\hline & $\begin{array}{l}\text { Abductor Pollicis } \\
\text { Longus }\end{array}$ & $3++$ & $3++$ & $3++$ \\
\hline & $\begin{array}{l}\text { Extensor } \\
\text { digitorum }\end{array}$ & $3+$ & $3+$ & $3+$ \\
\hline & Opponens Pollicis & $3++$ & 4 & 4 \\
\hline & Palmar Interossei & $3++$ & $3++$ & 4 \\
\hline & Dorsal Interossei & $3++$ & $3++$ & 4 \\
\hline & Lumbricals & 4 & 4 & 4 \\
\hline
\end{tabular}




\section{Cellular Therapy in progression of Becker's Muscular Dystrophy}

Eur J Transl Myol - Basic Appl Myol 2016; 26 (1): 61-66

he could perform his exercises with much ease. mMRCMMT(I) showed significant improvement in almost all the muscles (Table 2).

NSAA showed significant improvement at second follow up. FIM, BBS, Brooke and Vignos Scale scores remained the same post intervention suggesting that the progression of the disease was halted.

\section{Discussion}

BMD leads to slowly worsening disability due to decreased mobility and the ability to self care. They may have signs of cardiac involvement like palpitations, dizziness, syncope and dyspnea at rest or during exercise.

The management of BMD is multidisciplinary, which consist of medical management like use of corticosteroids which reduces the inflammatory breakdown of the muscle fibers. Rehabilitation intends to sustain the functional level and delay dependence but does not correct the course of the disease or pathology. ${ }^{1,9,10}$ Presently there are no definitive treatment strategy for control of disease progression or improvement of muscle strength. ${ }^{9}$

Gene therapy aims at introducing the absent dystrophin gene using various vectors. Several practical difficulties have prevented gene therapy from being a clinically feasible and viable option at present. ${ }^{11}$ Stem cell transplantation has been proposed as a treatment for such disorders. ${ }^{7}$ Cell-based therapies have been attempted to promote muscle regeneration, with the optimism that the host cells will recover the muscle function and pathology by repopulating the muscle. Stem cells were considered favourable for therapeutic applications for their capacity of self-renewal and differentiation potential. $^{12}$ Encouraging results have been obtained with adult stem cells to treat human diseases in recent years. ${ }^{1,5,6}$

Sharma et al., in 2013 studied the effect of Autologous BMMNCs transplantation in 150 patients with MD. After 12 months of follow up the patients showed improvement in muscle strength, and gait. Symptomatic and functional improvements were also seen in $86.67 \%$ cases, in which six patients showed decrease in fatty infiltration and muscle regeneration on MRI-MSK, and nine showed improvement in muscle electrical activity on EMG. ${ }^{6}$ Yang et al in 2009 also showed improvement in ADLs in progressive MD with stem cell transplantation. ${ }^{13}$ Haurd et al., Gussoni et al., Skuk et al., Mendell et al., Trembley et al., Zhang et al. and Torrente et al. have demonstrated the beneficial effects of various types of stem cell transplantation in MD. ${ }^{1}$

The MNCs consist of a variety of cells like hematopoietic stem cells, tissue-specific progenitor cells, stromal cells, and specialized blood cells in different stages of development. ${ }^{7}$ These cells posses the capability to mobilize and exert their reparative effects at the site of injury. They contribute to neovascularization and increase angiogenesis by producing signaling molecules like vascular endothelial growth factors and fibroblast growth factors (FGF2). They also promote tissue remodeling, prevent apoptosis, decrease inflammation, release growth factors, and activate the satellite cells. These are the paracrine effects that may help in bringing the desired outcome of the cellular therapy. ${ }^{14,15}$ Autologous BMMNCs were used in this case because they have no ethical issues and its safety has been established. ${ }^{16}$

Transplantation of stem cells into the desired location of the muscle body tends to be the major practical difficulty. Intravenous administration of bone marrow derived stem cells showed successful homing of the stem cells into the injured muscular tissues in animal models; however it also risks the dilution in the cell concentration. $\mathrm{MD}$ is primarily perceived as the disease of the muscles, few evidences suggest neuromuscular involvement. Dystrophin is a part of the structural protein found in the myelin forming Schwann cells and in nerves. Demyelination and degeneration like changes in the nerves may occur with such abnormalities in the cells. Therefore, two different modes of cell transplantation was chosen, intramuscular and intrathecal. The bone marrow MNCs were injected at the motor points of targeted weak muscles for the repair of innervating nerve as well as the muscles. CSF is known to harbor growth factors which helps the growth of the cortical epithelium and promotes vascularization in the nervous system so it was used as diluting medium. ${ }^{17}$

Exercise induces activation, mobilization and differentiation of stem cells and also secretes various growth factors which stimulates resident stem cells and improves skeletal muscle regeneration and function so in our study post transplantation included a physical rehabilitation program. ${ }^{18}$ A rehabilitation program was followed in which moderate exercises were performed which helped in the mobilization of the cells in the blood stream. ${ }^{19}$

Muscular strength was recorded by manual muscle testing, with a scale devised by our experienced physiotherapists based on the modified Medical Research Council's manual muscle testing scale (mMRC MMT). As mMRC-MMT is not sub-classified into grades 1 and 2 based on partial Range of Motion $(\mathrm{ROM})$, in our scale (mMRC MMT - I) grades 1 and 2 are subdivided. This allowed us to quantify the minimal changes in the strength as observed in patients with BMD (Table 2). There was increase in the muscle strength which was recorded in MMT as well as observed in the items of NSAA such as stepping up and sitting. Even functionally overhead activities and balance in standing and walking were improved. All the objective measures showed no deterioration in the scores.

A recent case study showed increase in the muscle fibers of peronei, gastrosoleus and long, medial and lateral head of triceps with decreased fatty infiltration as observed on the MRI-MSK post 6 months of cellular 


\section{Cellular Therapy in progression of Becker's Muscular Dystrophy}

Eur J Transl Myol - Basic Appl Myol 2016; 26 (1): 61-66

transplantation in BMD which is almost similar to our study. $^{20}$

An important cause of morbidity and mortality in MDs can be respiratory dysfunction but in our study there was marked improvement in the values of maximum inspiratory volume and PEFR from the baseline and there was reduction in the fatigue level and improvement in the endurance during the activities which could be due to the improvement in the respiratory muscle function.

To maintain the improvements achieved and to make the progression static repeating the procedure of cell therapy may be helpful. ${ }^{5}$ Cellular transplantation may cause regeneration of the degenerated muscles and may altere the disease progression in BMD. Although this case report is an observation of a single patient, it may support undertaking further research. Further robust analysis and large clinical trials with sophisticated methodology are required to establish the optimum dosage, source, and frequency of transplantation. One of the limitations of the study is that it has no control case to compare but since the patient showed halting of the progression only after cellular therapy we may postulate that the cell transplantation played a vital role.

In conclusion, the case report suggests that cellular therapy combined with rehabilitation may offer the possibility of repairing and regenerating muscle fibers decreasing the rate of progression of BMD.

\section{Authors' Contribution}

Study Design - Alok Sharma, Hemangi Sane, Nandini Gokulchandran

Data Collection - Rishabh Sharan, Amruta Paranjape, Jayanti Yadav

Data Interpretation - Rishabh Sharan, Amruta Paranjape, Pooja Kulkarni, Jayanti Yadav

Manuscript Preparation - Rishabh Sharan, Hemangi Sane, Pooja Kulkarni

Literature Search - Rishabh Sharan

\section{Conflict of Interest}

The authors declare no conflict of interests.

\section{Corresponding Author}

Pooja Kulkarni, Department of Research and Development, NeuroGen Brain and Spine Institute StemAsia Hospital \& Research Centre, Sector 40, Plot No 19, Opposite Rail Vihar, Near Seawood Station, Palm Beach Road, Seawood (W), Navi Mumbai 400706.

Email: publications@neurogen.in

\section{References}

1. Becker PE. Two families of benign sex-linked recessive muscular dystrophy. Rev Can Biol. 1962 Sep-Dec. 21:551-66.

2. Wallace GQ, McNally EM. Mechanisms of muscle degeneration, regeneration, and repair in the muscular dystrophies. Annu Rev Physiol 2009;71:37-57.

3. Torrente Y, Tremblay JP, Pisatet F, et al. Intraarterial injection of muscle-derived CD34+ Sca-1+ stem cells restores dystrophin in $\mathrm{mdx}$ mice. J Cell Biol 2001;152:335-48.

4. Meregalli M, Farini A, Parolini D, et al. Stem Cell Therapies to Treat Muscular Dystrophy Review Article. BioDrugs 2010;24:237-47.

5. Sharma A, Sane H, Paranjape A, et al. Autologous bone marrow mononuclear cell transplantation in Duchenne muscular dystrophy - a case report. Am J Case Rep 2014;15:128-34.

6. Sharma A, Sane H, Badhe P, et al. A Clinical Study Shows Safety and Efficacy of Autologous Bone Marrow Mononuclear Cell Therapy to Improve Quality Of Life in Muscular Dystrophy Patients. Cell Transplantation 2013;22:127-38.

7. Sharma A.; Gokulchnadran N, Sane H, Badhe P. 3rd eds. Stem cell therapy in neurological disorders. NeuroGen Brain and Spine Institute, Navi Mumbai, India. 2015

8. Petit I, Szyper-Kravitz M, Nagler A, et al. G-CSF induces stem cell mobilization by decreasing bone marrow SDF-1 and up-regulating CXCR4. Nature Immunolog 2002;3:687-94.

9. Bushby K, Finkel R, Birnkrant DJ et al. DMD Care Considerations Working Group. Diagnosis and management of Duchenne muscular dystrophy, part 1: diagnosis, and pharmacological and psychosocial management. Lancet Neurol 2010;9:77-93.

10. Manzur AY, Muntoni F, Diagnosis and new treatments in muscular dystrophies. Journal of Neurology, Neurosurgery and Psychiatry 2009;80:706-14.

11. Angelini C, Fanin M, Pegoraro E, et al. Clinicalmolecular correlation in 104 mild X-linked muscular dystrophy patients: characterization of sub-clinical phenotypes. Neuromuscul Disord 1994;4:349-58

12. Meregalli M, Farini A, Colleoni, F, et al. The role of stem cells in muscular dystrophies. Curr Gene Ther 2012;12:192-205.

13. Yang XF, Xu YF, Zhang YB, et al. Functional improvement of patients with progressive muscular dystrophy by bone marrow and umbilical cord blood mesenchymal stem cell transplantations. Zhonghua Yi Xue Za Zhi. 2009; 89:2552-6.

14. Vandervelde S, Luyn V, M. Tio J, Harmsen, MC. Signaling factors in stem cell mediated repair of 


\section{Cellular Therapy in progression of Becker's Muscular Dystrophy}

Eur J Transl Myol - Basic Appl Myol 2016; 26 (1): 61-66

infarcted myocardium. $\mathrm{J}$ Mol Cell Cardiol 2005;39:363-76.

15. Gnecchi M, Zhang Z, Ni A, Dzau VJ. Paracrine mechanisms in adult stem cell signaling and therapy. Circulation Research 2008;103:1204-19.

16. Sharma A, Gokulchandran N, Chopra G et al. Administration of autologous bone marrow-derived mononuclear cells in children with incurable neurological disorders and injury is safe and improves their quality of life. Cell Transplant 2012; 21: S79-90.

17. Miyan JA, Zendah M, Mashayekhi F, Owen-Lynch PJ. Cerebrospinal fluid supports viability and proliferation of cortical cells in vitro, mirroring in vivo development. Cerebrospinal Fluid Research 2006;3:2

18. Wahl P, Brixius K, Bloch W. Exercise-induced stem cell activation and its implication for cardiovascular and skeletal muscle regeneration. Minim Invasive Ther Allied Technol 2008;17:91-9.

19. Sveen ML, Jeppesen TD, Hauerslev $S$ et al. Endurance training improves fitness and strength in patients with Becker muscular dystrophy. Brain 2008;131:2824-31.

20. Sharma A, Paranjape A, Sane H, et al. Cellular Transplantation Alters the Disease Progression in Becker's Muscular Dystrophy. Case Reports in Transplantation. 2013. Article ID 909328, 7 pages. 